\title{
Age Related Changes in Cerebrovascular Reactivity and Its Relationship to Global Brain Structure
}

\author{
Gordon D. Waiter ${ }^{1^{*}}$, George G. Cameron ${ }^{1}$, Trevor S. Ahearn ${ }^{2}$, \\ Christian Schwarzbauer ${ }^{1}$ and Alison D. Murray ${ }^{1}$ \\ ${ }^{1}$ Aberdeen Biomedical Imaging Centre, Division of Applied Medicine, University of Aberdeen, \\ Research MRI Centre, Lilian Sutton Building, Foresterhill, Aberdeen, UK. \\ ${ }^{2}$ Department of Radiology, NHS Grampian, Aberdeen, UK.
}

\begin{abstract}
Authors' contributions
This work was carried out in collaboration between all authors. Authors GDW and CS designed the study, wrote the protocol, and wrote the first draft of the manuscript. Author GGC provided image analysis support. Author TSA provided the dual echo pulse sequence. Author ADM provided clinical reporting of all scans. All authors read and approved the final manuscript.

Article Information

DOI: 10.9734/BJMMR/2015/16889

Editor(s):

(1) Vijay K Sharma, Division of Neurology, Yong Loo Lin School of Medicine, National University of Singapore, National

University Hospital, Singapore.

Reviewers:

(1) Anonymous, Poland

(2) Anonymous, Switzerland.

Complete Peer review History: http://www.sciencedomain.org/review-history.php?iid=950\&id=12\&aid=8640
\end{abstract}

\author{
Original Research Article
}

Received $17^{\text {th }}$ February 2015

Accepted $19^{\text {th }}$ March 2015

Published $31^{\text {st }}$ March 2015

\section{ABSTRACT}

Introduction: There is growing evidence to suggest that vascular and CSF haemodynamic effects are related to structural changes in the ageing brain. We investigated these effects in a sample of healthy participants by measuring changes in cerebrovascular reactivity induced by hypercapnia and comparing these to global and ROI based cerebral volume measures.

Methods: Forty five participants aged 21 to 58 years (23 female) were recruited. Cerebrovascular reactivity was determined from hypercapnia induced BOLD signal change during two 3-minute intervals of breathing $6 \% \mathrm{CO}_{2}$, interleaved with three 2-minute intervals of breathing room air. Parametric maps of reactivity were calculated as the ratio of \% BOLD signal change to end-tidal $\mathrm{CO}_{2}(\mathrm{mmHg})$. High resolution 3D $\mathrm{T} 1$-weighted images were segmented and lateral ventricle volume and white matter hypointensity volume determined.

Results: Significant negative correlations between both grey matter $(p=.042)$ and white matter $(p=.021)$ reactivity and age were found and significant negative correlations between grey matter 
$(p=.013)$ and white matter $(p=.004)$ reactivity and lateral ventricle volume were also found while correcting for age and total intracranial volume. A significant negative correlation between white matter reactivity and white matter hypointensity volume was found $(p=.049)$ after correcting for age.

Conclusion: These results support the hypothesis that cerebrovascular haemodynamics influence structural brain changes that occur during normal ageing that are independent of the age of the individual.

Keywords: MRI; hypercapnia; dual echo; cerebrovascular reactivity; volume; white matter hypointensity.

\section{INTRODUCTION}

The ability of the cerebral vasculature to adapt rapidly to changes in arterial blood pressure or metabolic demand is essential to maintain normal brain function. Cerebrovascular reactivity (CVR) to a vasoactive stimulus (such as hypercapnia) is a well-established marker of cerebral hemodynamic integrity. In a Transcranial Doppler study of CVR to hypercapnia, a significant reduction has been reported in both $A D$ and Vascular Dementia (VaD) patients compared to controls [1]. A recent MRI study in ageing rodents has shown that lower hypercapnia-derived CVR predicts mild cognitive impairment [2] and may therefore provide supporting evidence to the search for the causes of dementia.

The current global prevalence of dementia is > 30 million and this is expected to treble over the next 40 years [3]. The UK prevalence is about 800,000 with estimated cost to the UK economy exceeding $£ 23$ billion. Brain changes associated with dementing illnesses, the most common of which is Alzheimer's disease (AD), impose a significant burden even before clinical symptoms are present. Understanding how the brain changes in late life and the impact of such changes on mental (cognitive) ability is not only crucial to understanding dementia but also for developing preventative and therapeutic strategies.

In a recent magnetic resonance imaging (MRI) study in normal, non-demented old people, we have shown that structural brain changes predict future dementia and death [4]. With age, the brain undergoes structural and functional changes which are thought to be responsible for cognitive decline [5-7].

Cerebral compliance, a property of the brain that describes its deformability or ability to expand and contract as blood is pumped from the heart, has been shown to be reduced in individuals with AD [8]. Hydrodynamic theory predicts that a reduction in arterial tree compliance (age related increased arterial stiffness) will lead to a reduction in conversion of the pulse pressure within the arterial tree to pulsatile flow. Essentially, this reduces the ability of the arterial tree to dampen the pulse pressure and results in a greater transmission of pulsation to the brain. This may cause enlarged perivascular spaces and via choroid plexus pulsation, cause ventricular dilation and elevated CSF pulsatility [9].

With age, there is also an increase in brain white matter hyperintensities (WMH). High $\mathrm{WMH}$ loads, i.e. total volume of white matter hyperintensities, are associated with reduced cognitive ability [1113] and with vascular risk factors such as hypertension [14]. However, their interaction with other measurable brain abnormalities in cognitive ageing, such as atrophy, is less well understood.

Although it has been shown that there are components of both subject demographics [15] and of brain structure, such as WMH lesion load and brain volume that contribute to variations in cognitive decline, there is still a significant unknown component. Evidence is beginning to emerge that points to a possible role for changes in the cerebrovasculature in the aetiology of agerelated cognitive decline. In an initial attempt to disambiguate some of those "unknown components", we employed a dual gradient/spinecho sequence to investigate the interaction of both the cerebral microvasculature (with spinecho images) and cerebral macrovasculature (with gradient-echo images) on brain structure. The aim of this study, therefore, was to test the hypothesis that there is an age related decline in cerebrovascular reactivity and an associated relationship between both lateral ventricle volume and white matter microstructural damage and reactivity. 


\section{METHODS}

\subsection{Participants}

Forty five healthy volunteers with no history of trauma or neurological disease were recruited (23 females; age range 21-58 years, 39.56 \pm 11.2 years) for this study. Informed and written consent was obtained from all participants and the protocol was approved by the College of Life Sciences and Medicine Ethics Review Board (CERB) of the University of Aberdeen.

Participants were positioned supine on the scanner table and wore an anaesthetics facemask (Quadralite, Intersurgical, Wokingham, UK). A specially designed unidirectional breathing circuit (Intersurgical, Wokingham, UK; product code 2013014) was used to deliver either room air or a room air $/ 6 \% \mathrm{CO}_{2}$ mix. An MRI-compatible patient monitor (Schiller MAGLIFE Serenity, SCHILLER AG, Baar, Switzerland) was used to continuously monitor physiological and respiratory parameters including heart rate, respiration rate, blood oxygenation, end-tidal $\mathrm{O}_{2}\left(\mathrm{EtO}_{2}\right)$ and end-tidal $\mathrm{CO}_{2}\left(\mathrm{EtCO}_{2}\right)$; parameters were sampled rate of $1 \mathrm{~Hz}$ and stored in a text file on a remote PC.

Blood pressure was measured, supine, before and after the reactivity imaging sequence, Table 1.

\subsection{MR Imaging}

MRI data were acquired on a Philips 3 T Achieva scanner (Philips Medical Systems, Best, The Netherlands) using the manufacturer's 32channel phased-array head coil.

\subsubsection{Structural imaging}

High-resolution structural images were acquired using a T1-weighted TFE sequence (TR=8.2ms; $\mathrm{TE}=3.8 \mathrm{~ms}$; flip angle $=8^{\circ}$; matrix size $=$ $240 \times 240 \times 160$; field of view $=240 \times 240 \times 160 \mathrm{~mm}^{3}$; voxel size $=1.0 \times 1.0 \times 1.0 \mathrm{~mm}^{3}$; and total acquisition time $=5 \mathrm{~min} 35 \mathrm{~s})$. These images were subsequently processed with the Freesurfer software package (http://surfer.nmr.mgh.harvard.edu) to measure cortical thickness and regional and global volumes.

\subsubsection{Hypercapnia imaging}

The signal response of gradient echo and spin echo sequences are different depending on the vasculature of the tissue, with gradient echo signals being sensitive to changes in the venous macrovasculature ( venous vessel radius $>50$ $\mu \mathrm{m})$ and spin echo signals being sensitive to changes in the venous microvasculature (venous vessel radius $<10 \mu \mathrm{m}$ ) [16]. A single-shot dualecho EPI sequence was therefore used for simultaneous acquisition of gradient-echo (GE) and spin-echo (SE) images [17]. Imaging parameters were $\mathrm{TR}=3.5 \mathrm{~s} ; \mathrm{TE}_{\mathrm{GE}} / \mathrm{TE}_{\mathrm{SE}}=30 / 80 \mathrm{~ms}$; flip angle $=90^{\circ}$; matrix size $=68 \times 67$; field of view= $200 \times 200 \mathrm{~mm}^{2}$; and in plane resolution $3 \times 3 \mathrm{~mm}^{2}$ ). 28 oblique transverse slices (slice thickness $=3.0$ $\mathrm{mm}$; inter-slice gap $=1.0 \mathrm{~mm}$ ) were acquired to cover the whole brain. Reactivity was calculated separately for both SE and GE images. Two 3minute blocks of hypercapnia (breathing a room air/6\% $\mathrm{CO}_{2}$ mix) were interleaved with three 2minute blocks of breathing room air, giving a total acquisition time of 12 minutes. Parametric maps of the cerebrovascular reactivity were calculated according to $\triangle \mathrm{BOLD} / \triangle \mathrm{EtCO}{ }_{2}$, where $\triangle \mathrm{BOLD}$ denotes the change in GE or SE signal intensity between hypercapnia and normocapnia and $\Delta \mathrm{EtCO}_{2}$ denotes the change in $\mathrm{EtCO}_{2}$ between hypercapnia and normocapnia.

\subsection{Image Analysis}

\subsubsection{Structural scan analysis}

For each participant, T1 images were first intensity normalised, then the boundaries between the grey matter and the white matter and the outer surface of the cortex (the pial surface) were determined. The cortical surface was then divided into 34 different anatomical regions per hemisphere including fusiform, inferior temporal and parahippocampal. The mean thickness of these regions was calculated on the basis of the boundary of the GM and WM and the outline of pial surface, respectively. In addition to cortical thickness a number of regional volume measurements were determined automatically by the Freesurfer software including lateral ventricle volume and white matter hypointensity volume. The segmentation process was manually validated and corrected as necessary.

\subsubsection{Hypercapnia image analysis}

It has been shown that there is a time lag between the BOLD signal and the $\mathrm{EtCO}_{2}$ concentration change induced by switching from the room air to $\mathrm{CO}_{2} /$ room air mix. To determine this lag on a subject by subject basis a 
preliminary region of interest analysis was performed. The mean BOLD signal with in an ROI defining the bilateral thalamus, determined from the Wake Forrest University Pickatlas (http://fmri.wfubmc.edu/software/PickAtlas), was correlated with the $\mathrm{EtCO}_{2}$ time course using the Matlab "cov" function. The shift at which the $\mathrm{EtCO}_{2}$ time course provided the maximum crosscorrelation coefficient with the BOLD signal was defined as the time lag. This time lag was used to correct the $\mathrm{EtCO}_{2}$ time courses for all subsequent analysis, Error! Reference source not found..

GE and SE BOLD images were pre-processed separately using Matlab (MATLAB 7.14, The Math Works Inc., Natick, MA, 2000) and the SPM8 software package (http://www.fil.ion.ucl.ac.uk/spm). First, each volume was realigned to match the spatial location of the first volume, and a mean image generated from all of the realigned images. The realigned GE and SEBOLD volumes were then co-registered with the high resolution structural scan.

Spatial normalisation parameters were determined by the SPM image segmentation routine and applied to the co-registered $\mathrm{GE}$ BOLD volumes. These parameters transformed the BOLD GE and SE volumes into Montreal Neurological Institute (MNI) standard space. These volumes were re-sampled to a resolution of $2 \mathrm{~mm}$ isotropic and smoothed with an $8 \mathrm{~mm}$ full width at half maximum isotropic Gaussian spatial smoothing kernel.

To determine Cerebrovascular Reactivity (CVR), the shifted $\mathrm{EtCO}_{2}$ time courses were correlated with the smoothed, spatially normalised GE and SE BOLD volumes on a voxel by voxel basis using a general linear model procedure, Fig. 2. Microvascular reactivity was calculated in a subset of participants.

\subsection{Statistical Analysis}

Voxel based data analysis was performed using the General Linear Model as implemented by SPM8. Analysis of demographic and ROI based data was performed using $R$ (http://www.rproject.org version 3.0.0). A Tukey Honest Significances Difference test was used to identify differences between age decades for structural and haemodynamic measures while correcting for multiple comparisons. Pearson correlation was used to investigate whether linear relationships existed between age and structural and haemodynamic measures. Sex differences in structural and haemodynamic measures were investigated using a two sample $t$ test. Results were expressed as mean $\pm S D$. Correction of probability thresholds for multiple comparisons was implemented using the Holm [18] method implemented in the $\mathrm{R}$ software package (i.e., p. adjust function with the "Holm" option). A result with a corrected $\mathrm{p}<.05$ was considered statistically significant.

\section{RESULTS}

Of the 45 participants who volunteers who took part in the study, 41 completed the scanning session. Of the 4 who did not, 2 were claustrophobic, 1 had a metal plate in their neck and 1 had an incidental finding that required clinical follow-up. Of the remaining 41 participants, 3 reactivity data sets could not be analysed. This was due to an ill fitting mask in 1 participant and corrupt log files in 2 others. No participants who completed the scanning session reported any discomfort either during or after the session. Table 1 summarises the physiological parameters for each decade, as well as the sampleas a whole.

\subsection{Physiological Measures}

Significant differences in Diastolic BP between the 30 s and 40 s and the 30 s and 50 s groups $(p=.037$ and $p=.044$ respectively) were found. No significant age related differences were found in any other measures (i.e. Systolic BP, Room air EtCO2 and hypercapnia $\mathrm{EtCO}_{2}$ ). However, as expected, a significant increase in $\mathrm{EtCO}_{2}$ was found when breathing room air mixed with $6 \%$ $\mathrm{CO}_{2}$ (hyparcapnia) when compared to breathing room air alone $\left(\Delta \mathrm{EtCO}_{2}=10.72 \pm 2.29 \% / \mathrm{mmHg}\right.$, $\mathrm{p}<.001)$. Regrouping the cohort by sex, we found a trend towards significantly higher diastolic BP in males than in females $(p=.09)$, and a significantly higher systolic BP in males than in females $(p=.05)$, with a significant difference in $\mathrm{EtCO}_{2}$ when breathing room air between males and females $(p=.0006)$ and a significant difference in $\mathrm{EtCO}_{2}$ when breathing $6 \% \mathrm{CO}_{2}$ mixed with room air between males and females $(p=.04)$, Table 2. 


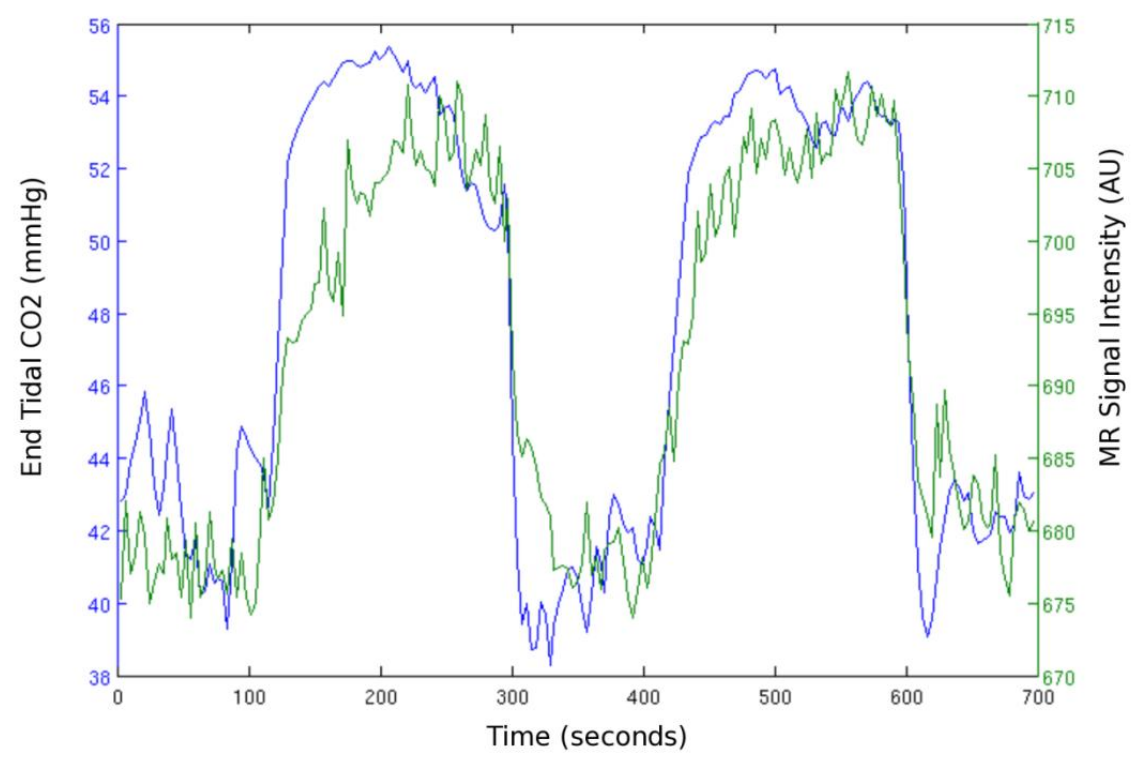

Fig. 1. GE BOLD signal intensity $\mathrm{AU}$ (green) and EtCO2 $\mathrm{mmHg}$ (blue) time courses

Table 1. Physiological parameters during room air and $\mathrm{CO}_{2}$ breathing

\begin{tabular}{llllll}
\hline Age group & $\begin{array}{l}\text { Age } \\
\text { (Years) }\end{array}$ & $\begin{array}{l}\text { Systolic BP } \\
(\mathbf{m m H g})\end{array}$ & $\begin{array}{l}\text { Diastolic BP } \\
(\mathbf{m m H g})^{\star}\end{array}$ & $\begin{array}{l}\text { End Tidal } \mathbf{C O}_{2} \\
(\mathbf{m m H g})\end{array}$ & $\begin{array}{l}\text { End Tidal } \mathbf{C O}_{2} \\
(\mathbf{m m H g})\end{array}$ \\
\cline { 5 - 6 } & & & & Room Air & $\mathbf{6 \% ~ \mathbf { C O } _ { 2 }}$ \\
\hline $20-29(\mathrm{~N}=10)$ & $25.48 \pm 2.7$ & $116.3 \pm 7.02$ & $71.44 \pm 8.02$ & $40.07 \pm 4.24$ & $51.08 \pm 2.56$ \\
$30-39(\mathrm{~N}=11)$ & $34.16 \pm 3.17$ & $112.6 \pm 10.1$ & $67.22 \pm 10.4$ & $41.71 \pm 2.43$ & $51.62 \pm 2.68$ \\
$40-49(\mathrm{~N}=8)$ & $45.28 \pm 3.41$ & $120.2 \pm 13.5$ & $79.22 \pm 10.9$ & $40.31 \pm 2.52$ & $51.55 \pm 3.02$ \\
$50-59(\mathrm{~N}=9)$ & $54.29 \pm 2.96$ & $123.5 \pm 8.86$ & $79.25 \pm 4.80$ & $40.33 \pm 1.69$ & $51.21 \pm 3.11$ \\
Sample $(\mathrm{N}=38)$ & $38.98 \pm 11.4$ & $118.0 \pm 10.6$ & $74.14 \pm 10.0$ & $40.65 \pm 3.29$ & $51.36 \pm 2.73$ \\
\hline
\end{tabular}

\subsection{Haemodynamic Measures}

When investigating the age dependence of global reactivity in the microvasculature (Table 3) (determined from gradient echo BOLD signal changes) significant negative correlations between age of participant and GM global reactivity $\left(R^{2}=.084, p=.043\right)$ and between age of participant and WM global reactivity were found $\left(R^{2}=.114, p=.022\right)$, as illustrated in

Fig. 3. No significant relationship was found when investigating the global reactivity in the microvasculature (determined from spin echo BOLD signal changes) in either grey matter or white matter.

\subsection{Global Structural Measures}

When investigating age related changes in global structural measures (see Table 4), we found a significant increase in lateral ventricle volume for the 50s group $(p=.015$ compared to the $40 \mathrm{~s}$ group), as shown in Fig. 4a. We also found a significant negative correlation between Age and Mean Cortical Thickness $\left(\mathrm{R}^{2}=.45, \mathrm{p}<.001\right)$ and a related negative correlation between Age and Total Grey Volume $\left(\mathrm{R}^{2}=.21, \mathrm{p}=.002\right)$, as illustrated in Fig. 4b.

\subsection{Comparison of Haemodynamic Measures and Global Structural Volumes}

We found a significant negative correlation between both grey matter $\left(R^{2}=.127, p=.013\right)$ and white matter $\left(\mathrm{R}^{2}=.221, \mathrm{p}=.004\right)$ macrovascular reactivity and total lateral ventricle volume while correcting for age and total intracranial volume, as shown in Fig. 5. We also found a significant negative correlation between white matter macrovascular reactivity and white matter hypointensity volume $\left(R^{2}=.185, p=.049\right)$ after correcting for age (see Fig. 6). No such correlation was found for grey matter 
macrovascular reactivity or either grey or white microvascular reactivity. No correlation was found between either grey matter volume or white matter volume and either grey or white matter reactivity, while correcting for total intracranial volume.

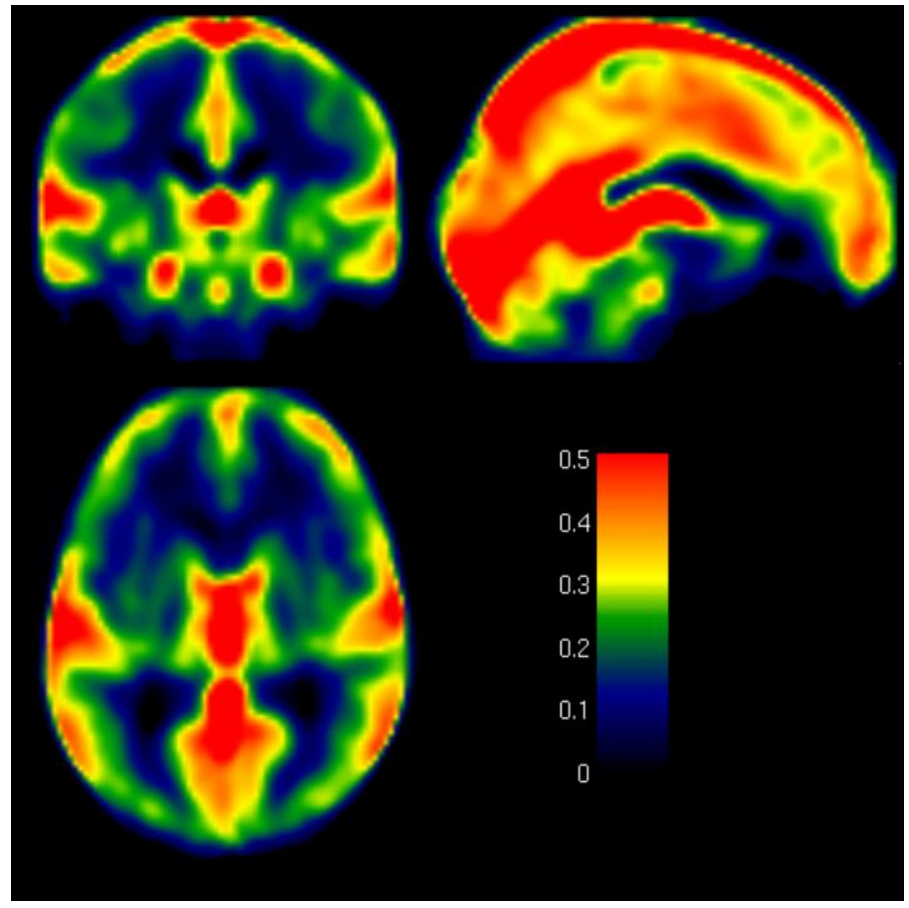

Fig. 2. Three plane view of mean cerebrovascular Reactivity (\%BOLD/mmHg) determined from gradient echo signal changes for the sample as a whole
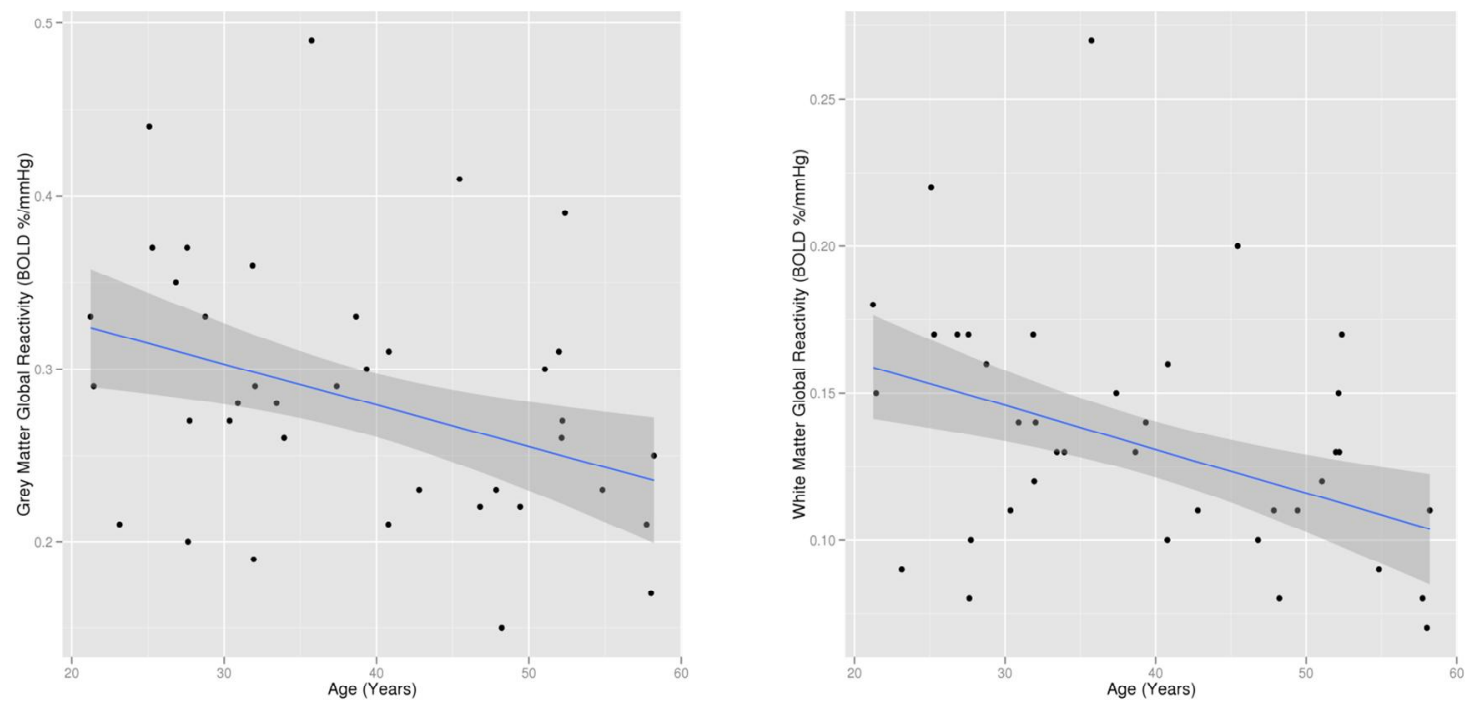

Fig. 3. Correlation of age and global reactivity (calculated from gradient echo signal changes) for grey matter (A) and white matter (B). The blue line represents the best linear fit and the shaded area shows the $95 \%$ confidence limits of the fit 
Table 2. Sex differences in physiological parameters during room air and $6 \% \mathrm{CO}_{2}$ breathing

\begin{tabular}{llllll}
\hline Gender & $\begin{array}{l}\text { Age } \\
(\text { Years })\end{array}$ & $\begin{array}{l}\text { Systolic BP } \\
(\mathbf{m m H g})\end{array}$ & $\begin{array}{l}\text { Diastolic BP } \\
(\mathbf{m m H g})\end{array}$ & $\begin{array}{l}\text { End Tidal } \mathbf{C O}_{2} \\
(\mathbf{m m H g})\end{array}$ & $\begin{array}{l}\text { End Tidal } \mathbf{C O}_{2} \\
(\mathbf{m m H g})\end{array}$ \\
\hline & & & & Room Air & $\mathbf{6 \%} \mathbf{C O}_{2}$ \\
\hline Male $(\mathrm{N}=18)$ & $37.80 \pm 10.3$ & $120.3 \pm 9.33$ & $76.76 \pm 10.6$ & $42.19 \pm 2.32$ & $52.0 \pm 2.78$ \\
Female $(\mathrm{N}=20)$ & $40.05 \pm 12.0$ & $116.0 \pm 10.8$ & $70.81 \pm 8.74$ & $39.17 \pm 2.69$ & $50.50 \pm 2.44$ \\
\hline
\end{tabular}

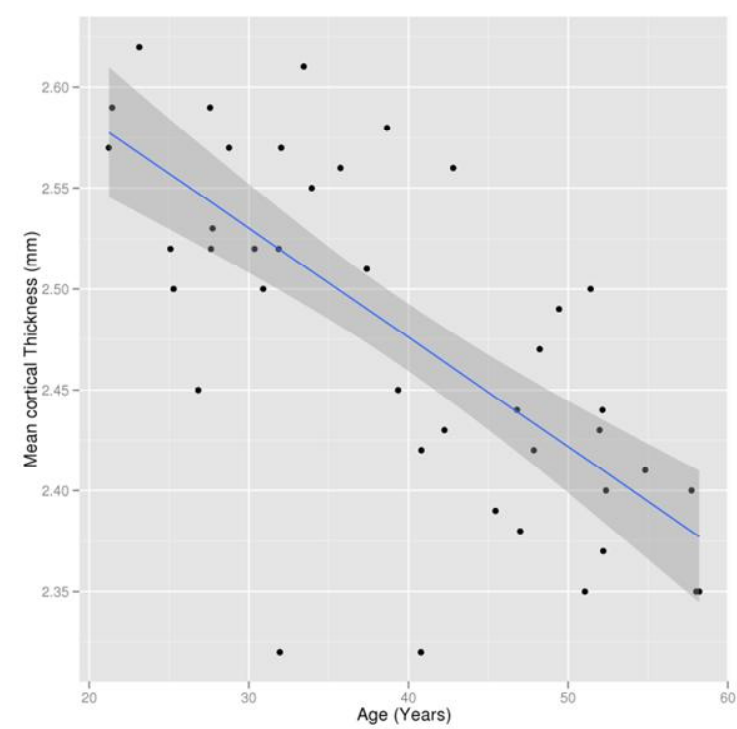

Fig. 4. Age related changes in mean cortical thickness (line represents a linear fit to the data, shaded area shows the $95 \%$ confidence limits of the fit)
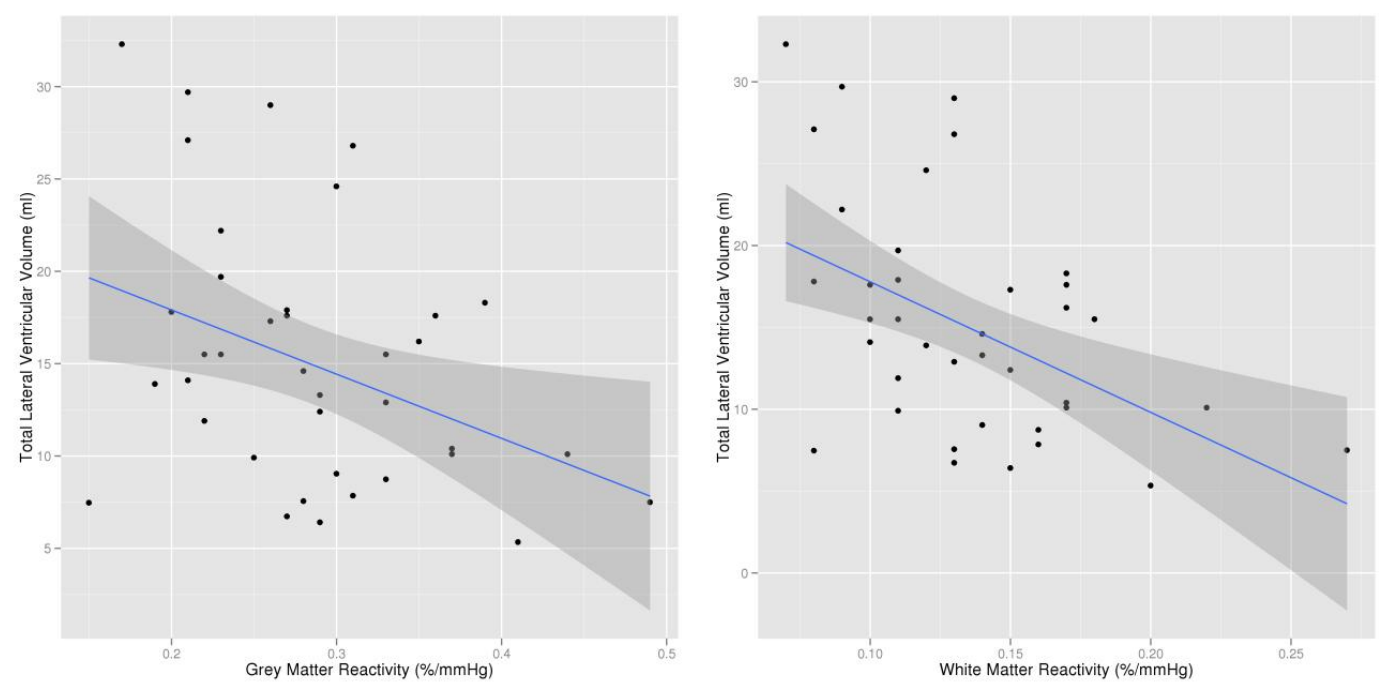

Fig. 5. Correlation of age and global macrovascular reactivity for grey matter (A) and white matter (B). The blue line represents the best linear fit and the shaded area shows the $95 \%$ confidence limits of the fit 


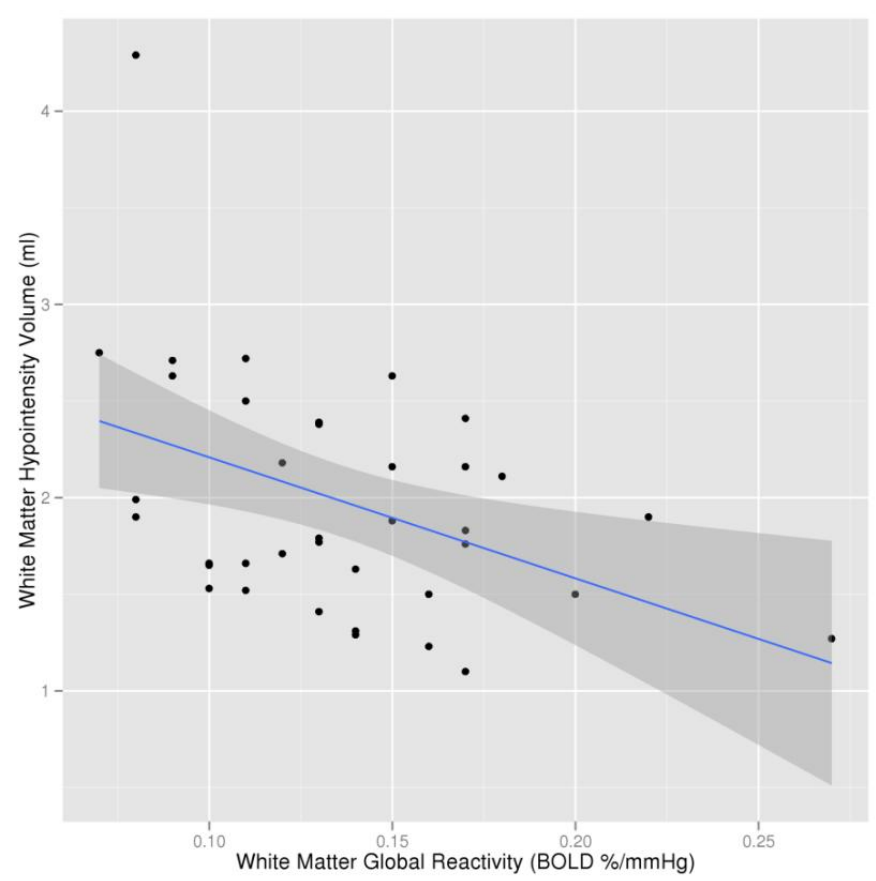

Fig. 6. Significant negative correlation between white matter hypointensity volume and white matter macrovascular reactivity after correcting for age. The blue line represents the best linear fit and the shaded area shows the $95 \%$ confidence limits of the fit

Table 3. Age related differences in grey matter (GM) and white matter (WM) cerebrovascular reactivity. The number in each group are given in Table 1

\begin{tabular}{llllc}
\hline $\begin{array}{l}\text { Age } \\
\text { group }\end{array}$ & $\begin{array}{l}\text { GM global reactivity } \\
(\% / m m H g)\end{array}$ & $\begin{array}{l}\text { WM global reactivity } \\
(\% / m m H g)\end{array}$ & $\begin{array}{l}\text { GM global reactivity WM global reactivity } \\
(\% / m m H g)\end{array}$ & $\begin{array}{l}\text { W/mmHg) } \\
\text { (\%/mm }\end{array}$ \\
\hline & & Gradient Echo BOLD & & Spin Echo BOLD \\
\hline $20-29$ & $.312 \pm .074$ & $.149 \pm .044$ & $.444 \pm .140$ & $.244 \pm .105$ \\
$30-39$ & $.306 \pm .078$ & $.148 \pm .043$ & $.525 \pm .149$ & $.275 \pm .086$ \\
$40-49$ & $.247 \pm .078$ & $.121 \pm .039$ & $.416 \pm .135$ & $.223 \pm .073$ \\
$50-59$ & $.265 \pm .063$ & $.117 \pm .032$ & $.447 \pm .102$ & $.220 \pm .049$ \\
Cohort $.280 \pm .075$ & $.135 \pm .042$ & $.462 \pm .135$ & $.242 \pm .082$ \\
\hline
\end{tabular}

Table 4. Age differences in global structural volume measures. The numbers in each group are given in Table 1

\begin{tabular}{lllllll}
\hline $\begin{array}{l}\text { Age } \\
\text { group }\end{array}$ & $\begin{array}{l}\text { Lateral } \\
\text { ventricle } \\
\text { volume }(\mathbf{m l})\end{array}$ & $\begin{array}{l}\text { Total grey } \\
\text { volume }(\mathrm{ml})\end{array}$ & $\begin{array}{l}\text { Brain } \\
\text { volume }(\mathrm{ml})\end{array}$ & $\begin{array}{l}\text { Intra-cranial } \\
\text { volume }(\mathbf{m l})\end{array}$ & $\begin{array}{l}\text { Brain } \\
\text { volume } \\
\text { fraction }\end{array}$ & $\begin{array}{l}\text { Mean cortical } \\
\text { thickness }(\mathbf{m m})\end{array}$ \\
\hline $20-29$ & $14.26 \pm 6.74$ & $693 \pm 36.7$ & $1422 \pm 82.8$ & $1569 \pm 157$ & $.912 \pm .079$ & $2.54 \pm .051$ \\
$30-39$ & $14.15 \pm 6.05$ & $650 \pm 61.5$ & $1351 \pm 113$ & $1441 \pm 156$ & $.941 \pm .065$ & $2.51 \pm .079$ \\
$40-49$ & $12.17 \pm 4.93$ & $612 \pm .32 .9$ & $1292 \pm 56.6$ & $1409 \pm 65.3$ & $.918 \pm .045$ & $2.44 \pm .071$ \\
$50-59$ & $20.58 \pm 8.36$ & $613 \pm 72.9$ & $1338 \pm 116$ & $1440 \pm 197$ & $.933 \pm .069$ & $2.39 \pm .035$ \\
Cohort & $15.28 \pm 7.09$ & $644 \pm 66.4$ & $1354 \pm 117$ & $1473 \pm 159$ & $.927 \pm .065$ & $2.48 \pm .087$ \\
\hline
\end{tabular}

\section{DISCUSSION AND CONCLUSION}

In this study, we used $6 \% \mathrm{CO}_{2}$ inhalation and a dual echo "BOLD sensitive" imaging sequence to investigate age related changes in both microand macrovascular cerebral reactivity. We found a significant negative correlation between age and macrovascular cerebral reactivity, 
determined from hypercapnia induced gradient echo BOLD signal change, in both cerebral grey and white matter and a significant negative correlation between macrovascular reactivity in white matter and white matter hypointensity volume, that is independent of age.

The calculated macrovascular cerebral reactivity values found here are similar, although slightly lower, than those previously reported in the literature $[19,20]$. Neither Zande et al. [19] nor Yezhuvath et al. [20] investigated the age dependence of cerebrovascular reactivity. This is probably due to their sample sizes being considerably smaller (11 and 13) compared to the size of the current study (41). Yezhuvath et al. [21] found significant reductions in frontal lobe cerebrovascular reactivity in patients with Alzheimer's disease compared with age matched controls and also showed that white matter hyperintensity volume correlated with the total volume of low reactivity brain regions in the $A D$ group. This agrees in part with our findings which show that the T1 estimated white matter hypointensity volume negatively correlates with global reactivity. In other words both studies show that low cerebrovascular reactivity is associated with increased white matter damage and, as we show, this is evident in otherwise healthy individuals.

Murray et al. [13] showed that brain white matter hyperintensity burden has a significant negative effect on life-long cognitive decline and demonstrated that the negative effect of hypertension on late life ability is all mediated by white matter hyperintensity burden.

Alzheimer's disease, the most common cause of dementia, involves a progressive decline in memory and cognition that correlates with synaptic and neuronal dysfunction and loss [22]. Alzheimer's disease is associated with cerebrovascular changes that precede clinical symptoms of the disease, worsen over the course of degeneration, and exacerbate cognitive decline. This is shown by impaired vascular tone, resting hypoperfusion and reduced haemodynamic responses to stimulation [23-26]. Post-mortem histology has shown various changes in blood vessel morphology in the Alzheimer's disease brain: Decreased vascular density, increased vessel curvature [27], degeneration of smooth muscle cells, vascular endothelium alterations [28], capillary fragmentation and abnormal blood-brain barrier permeability [29]. Whether such vascular changes are fundamental to Alzheimer's disease or represent co-existing vascular pathology, which makes the clinical expression of dementia more likely remains a topic of discussion [30]. It may be that these changes in blood vessel morphology can be assessed via cerebrovascular reactivity, providing an objective measure of microvascular pathology and vulnerability to dementia.

Alzheimer's disease is not the only dementia that has links to microvascular pathology. Vascular dementia, considered to be the second most common cause of dementia, has several different causes, but the two most common types are dementia resulting from multiple small or large strokes [31,32] and dementia related to ischemic white-matter lesions (WMLs) [33]. Cerebrovascular reactivity may provide a way to investigate the differences, if any, between Alzheimer's and vascular dementia.

Decline in cognitive ability typically begins in late mid-life, although it may manifest at any time from the late 40's onwards. To provide an estimate of the early trajectory of age related changes in cerebral reactivity we chose to investigate a group in the early to middle aged range. By investigating this age group we hoped to determine the effects of cerebral reactivity in an age range where cognitive decline is unlikely to be present, or if present, to have progressed to a level not currently measureable using current instruments.

There are limitations to this study. By using the thalamus as a region of interest to determine BOLD signal-EtCO ${ }_{2}$ time delay [20] we are assuming that this time delay is constant across the brain. A voxel by voxel determination of the off-set would eliminate this potential issue; however it may be that noise levels at the voxel level would significantly compromise the correlation analysis. It may be that there are age related differences in this off-set and this should be investigated in the future. No correlation was found between white matter micro-vascular reactivity, as determined by spin-echo imaging, and age or white matter hypointensity volume. Spin-echo (SE) images are sensitive to susceptibility changes from the venous microvasculature (vessel radii $<50 \mu \mathrm{m}$ ) where as gradient-echo (GE) images are sensitive to susceptibility changes in the venous macrovasculature (vessel radii $>50 \mu \mathrm{m}$ ). This suggests that the cerebrovascular reactivity in the venous microvasculature in both grey and 
white matter has relatively lower age dependence. However, the signal and therefore the signal to noise ratio (SNR) of the SE images is much lower than that of the GE images. This may explain why no correlation with microvascular reactivity was demonstrated.

Blood pressure is closely related to perfusion pressure which is the driving force for blood flow. An increase in blood pressure during hypercapnia can contribute to an increase in blood flow. However, we did not find an increase in blood pressure during $\mathrm{CO}_{2}$ breathing and suggest that changes in cerebrovascular reactivity found here are not due to blood pressure induced increases in blood flow that would cause changes in susceptibility related signal change.

In studies investigating the effects of white matter lesion load on cognitive ability, white matter lesion extent is typically assessed using either a T2-weighted or fluid attenuated inversion recovery (FLAIR) weighted image with visual assessment using a grading scale. The current study determined white matter hypointensity volume from an automated segmentation method applied to T1-weighted images, as implemented by the Free surfer software package, which also provided cortical thickness and ventricle volumes. We looked at a relatively young population with a relatively small range of white matter hypointensity volumes. In adults with relatively few white matter hypo/hyperintensities the increased signal to noise afforded by the T1weighted images may be more accurate. White matter hypointensities determined from T1weighted images have been used extensively to investigate white matter damage in multiple sclerosis [34] where they may reflect varying degrees of demyelination, with increasing lesion hypointensity corresponding to more breakdown in the structure. A larger sample, that includes participants with a larger range of white matter hypointensity volume, imaged with both T1weighted and FLAIR imaging, would be required to determine if the linear relationship between white matter hyper/hypointensity volume and cerebrovascular reactivity is valid and continues beyond age 60 .

In conclusion, we believe that cerebrovascular reactivity is a component of brain pathophysiology that is age dependent and that there is a strong correlation between cerebrovascular reactivity and white matter hypointensity that is, in turn, independent of age.
These results support the hypothesis that cerebrovascular haemodynamics influence structural brain changes that occur during normal ageing that are independent of the age of the individual.

\section{ACKNOWLEDGMENTS}

This study was funded by Alzheimer's Research UK (ARUK) and the Aberdeen Biomedical Imaging Centre, University of Aberdeen. GDW, $A D M$ and $C S$ are part of the SINASPE collaboration (Scottish Imaging Network - A Platform for Scientific Excellence www.SINAPSE.ac.uk). The authors thank Gordon Buchan, Baljit Jagpal, Nichola Crouch, Beverly Maclennan and Katrina Klaasen for their help with running the experiment and Dawn Younie and Teresa Morris for their help with recruitment and scheduling. We also thank the residents of Aberdeen and Aberdeenshire, and further afield, for their generous participation.

\section{COMPETING INTERESTS}

Authors have declared that no competing interests exist.

\section{REFERENCES}

1. Vicenzini E, Ricciardi MC, Altieri $M$, Puccinelli F, Bonaffini N, Di Piero V, Lenzi GL. Cerebrovascular reactivity in degenerative and vascular dementia: A transcranial doppler study. EurNeurol. 2007;58:84-89.

2. Mitschelen $M$, Garteiser $P$, Carnes BA, Farley JA, Doblas $S$, DeMoe JH, Warrington JP, Yan $\mathrm{H}$, Nicolle MM, Towner $\mathrm{R}$, Sonntag WE. Basal and hypercapniaaltered cerebrovascular perfusion predict mild cognitive impairment in aging rodents. Neuroscience. 2009;164:918-928.

3. Barnes DE, Yaffe K. The projected effect of risk factor reduction on Alzheimer's disease prevalence. The Lancet Neurology. 2011;10:819-828.

4. Staff RT, Murray AD, Ahearn T, Salarirad S, Mowat D, Starr JM, Deary IJ, Lemmon $\mathrm{H}$, Whalley LJ. Brain volume and survival from age 78 to 85: The contribution of alzheimer-type magnetic resonance imaging findings. J Am Geriatr Soc. 2010;58:688-695.

5. Staff RT, Murray AD, Deary IJ, Whalley LJ. Generality and specificity in cognitive 
aging: A volumetric brain analysis. Neurolmage. 2006;30:1433-1440.

6. Radoš $M$, Judaš $M$, Kostović I. In vitro MRI of brain development. Eur $\mathrm{J}$ Radiol. 2006;57:187-198.

7. Meltzer CC, Becker JT, Price JC, MosesKolko E. Positron emission tomography imaging of the aging brain. Neuroimaging Clin N Am. 2003;13:759-767.

8. Bateman GA, Levi CR, Schofield P, Wang $Y$, Lovett EC. The pathophysiology of the aqueduct stroke volume in normal pressure hydrocephalus: Can co-morbidity with other forms of dementia be excluded? Neuroradiology. 2005;47:741-748.

9. Johanson CE, Duncan III JA, Klinge PM, Brinker T, Stopa EG, Silverberg GD. Multiplicity of cerebrospinal fluid functions: New challenges in health and disease. Cerebrospinal Fluid Research. 2008;5.

10. Inatomi $\mathrm{Y}$, Yonehara $\mathrm{T}$, Hashimoto $\mathrm{Y}$, Hirano T, Uchino M. Correlation between ventricular enlargement and white matter changes. Journal of the Neurological Sciences. 2008;269:12-17.

11. Leaper SA, Murray AD, Lemmon HA, Staff RT, Deary IJ, Crawford JR, Whalley LJ. Neuropsychologic correlates of brain white matter lesions depicted on MR images: 1921 Aberdeen birth cohort. Radiology. 2001;221:51-55.

12. Saczynski JS, Jonsdottir MK, Sigurdsson S, Eiriksdottir G, Jonsson PV, Garcia ME, Kjartansson $\mathrm{O}$, Van Buchem MA, Gudnason V, Launer LJ. White matter lesions and cognitive performance: The role of cognitively complex leisure activity. Journals of Gerontology - Series A Biological Sciences and Medical Sciences. 2008;63:848-854.

13. Murray AD, Staff RT, McNeil CJ, Salarirad S, Starr JM, Deary IJ, Whalley LJ. Brain lesions, hypertension and cognitive ageing in the 1921 and 1936 Aberdeen birth cohorts. Age. 2012;34:451-459.

14. Murray AD, Staff RT, Shenkin SD, Deary IJ, Starr JM, Whalley LJ. Brain white matter hyperintensities: Relative importance of vascular risk factors in nondemented elderly people. Radiology. 2005;237:251-257.

15. Reed BR, Mungas D, Farias ST, Harvey D, Beckett L, Widaman K, Hinton L, DeCarli C. Measuring cognitive reserve based on the decomposition of episodic memory variance. Brain. 2010;133:2196-2209.
16. Boxerman JL, Hamberg LM, Rosen BR, Weisskoff RM. MR contrast due to intravascular magnetic susceptibility perturbations. Magnetic Resonance in Medicine.1995;34:555-566.

17. Schwarzbauer C, Mildner T, Heinke W, Brett M, Deichmann R. Dual echo EPI The method of choice for fMRI in the presence of magnetic field inhomogeneities? Neuroimage. 2010;49: 316-326.

18. Holm S. A simple sequentially rejective multiple test procedure. Scandinavian Journal of Statistics. 1979;6:65-70.

19. Zande $\mathrm{FH}$, Hofman PA, Backes WH. Mapping hypercapnia- induced cerebrovascular reactivity using BOLD MRI. Neuroradiology. 2005;47:114-120.

20. Yezhuvath US, Lewis-Amezcua K, Varghese R, Xiao G, Lu H. On the assessment of cerebrovascular reactivity using hypercapnia BOLD MRI. NMR Biomed. 2009;22:779-786.

21. Yezhuvath US, Uh J, Cheng Y, MartinCook K, Weiner M, Diaz-Arrastia R, van Osch M, Lu H. Forebrain-dominant deficit in cerebrovascular reactivity in Alzheimer's disease. Neurobiol Aging. 2012;33:75-82.

22. Querfurth HW, LaFerla FM. Alzheimer's disease. N Engl J Med. 2010;362:329-344.

23. Miao J, Xu F, Davis J, Otte-Höller I, Verbeek MM, Van Nostrand WE. Cerebral microvascular amyloid $\beta$ protein deposition induces vascular degeneration and neuroinflammation in transgenic mice expressing human vasculotropic mutant amyloid $\beta$ precursor protein. Am J Pathol. 2005;167:505-515.

24. Girouard H, ladecola C. Neurovascular coupling in the normal brain and in hypertension, stroke and Alzheimer disease. J Appl Physiol. 2006;100:328335.

25. Shin HK, Jones PB, Garcia-Alloza M, Borrelli L, Greenberg SM, Bacskai BJ, Frosch MP, Hyman BT, Moskowitz MA, Ayata C. Age-dependent cerebrovascular dysfunction in a transgenic mouse model of cerebral amyloid angiopathy. Brain. 2007;130:2310-2319.

26. Takano T, Han X, Deane R, Zlokovic B, Nedergaard $M$. Two-photon imaging of astrocytic $\mathrm{Ca} 2+$ signaling and the microvasculature in experimental mice models of Alzheimer's disease. Annals of the New York Academy of Sciences. 2007;1097:40-50. 
27. Fischer VW, Siddiqi A, Yusufaly Y. Altered angioarchitecture in selected areas of brains with Alzheimer's disease. Acta Neuropathol. 1990;79:672-679.

28. Kalaria RN. Small vessel disease and alzheimer's dementia: Pathological considerations. Cerebrovascular Diseases. 2002;13:48-52.

29. Perlmutter LS. Microvascular pathology and vascular basement membrane components in Alzheimer's disease. Mol Neurobiol. 1994;9:33-40.

30. Brickman AM, Muraskin J, Zimmerman ME. Structural neuroimaging in Alzheimer's disease: Do white matter hyperintensities matter? Dialogues in Clinical Neuroscience. 2009;11:181-190.

31. Skoog I. Risk factors for vascular dementia: A review. Dementia. 1994;5: 137-144.

32. Roman GC, Tatemichi TK, Erkinjuntti T, Cummings JL, Masdeu JC, Garcia JH,
Amaducci L, Orgogozo J-, Brun A, Hofman A, Moody DM, O'Brien MD, Yamaguchi T, Grafman J, Drayer BP, Bennett DA, Fisher M, Ogata J, Kokmen E. Vascular dementia: Diagnostic criteria for research studies: Report of the NINDS-AIREN International Workshop. Neurology. 1993;43:250-260.

33. Tatemichi TK, Desmond DW, Paik M, Figueroa M, Gropen TI, Stern Y, Sano M, Remien R, Williams JBW, Mohr JP, Mayeux R. Clinical determinants of Dementia related to stroke. Ann Neurol. 1993;33:568-575.

34. Loevner LA, Grossman RI, McGowan JC, Ramer KN, Cohen JA. Characterization of multiple sclerosis plaques with T1weighted MR and quantitative magnetization transfer. Am J Neuroradiol. 1995;16:1473-1479.

(C) 2015 Waiter et al.; This is an Open Access article distributed under the terms of the Creative Commons Attribution License (http://creativecommons.org/licenses/by/4.0), which permits unrestricted use, distribution, and reproduction in any medium, provided the original work is properly cited.

Peer-review history:

The peer review history for this paper can be accessed here: http://www.sciencedomain.org/review-history.php?iid=950\&id=12\&aid=8640 